\title{
State-of-the-art blood conservation strategies following repair of aortic aneurysms and acute aortic dissection
}

\author{
Katharina Schulte MB, Rizwan Attia MRCS
}

\begin{abstract}
K Schulte, R Attia. State-of-the-art blood conservation strategies following repair of aortic aneurysms and acute aortic dissection. Curr Res Cardiol 2014;1(1):17-22.
\end{abstract}

Cardiac surgery is associated with excessive bleeding and complex aortic surgery poses a higher risk for bleeding diathesis. Predictors of bleeding include patient factors such as older age, emergency surgery, lower body surface area and the use of perioperative antiplatelet agents. Operative factors include prolonged cardiopulmonary bypass $(\mathrm{CPB})$ time, complexity of surgery, reoperative surgery and prolonged hypothermia. Between $2 \%$ and $15 \%$ of patients require re-exploration for bleeding. Although a surgically correctable source is found in $50 \%$ to $67 \%$ of cases, bleeding and surgical re-exploration are independent predictors of adverse outcome. The use of allogeneic transfusions is associated with numerous adverse outcomes such as an increase in nosocomial infection and mortality in critically ill patients. Blood conservation strategies and steps to minimize bleeding are the desired clinical goal. Preoperative antiplatelet agents are limited when

Datients surgically treated for thoracic aortic aneurysms, acute aortic 1 syndromes encompassing type A intramural hematoma, penetrating aortic ulcers and acute type A aortic dissection area at an increased risk for blood loss that can complicate surgical repair (1) and lead to life-threatening coagulopathy (2). Major blood loss is defined as a loss of $\geq 20 \%$ total blood volume. Five to seven percent of cardiac surgery procedures are associated with severe bleeding and up to $50 \%$ of patients require blood transfusions (3). This increases complication rates, length of intensive care unit (ICU) stay, incidence of multisystem organ failure, hospital stay and mortality. There are multiple factors that are responsible including patient hypothermia, hemodilution, fibrinolysis, platelet dysfunction, and activation of a proinflammatory coagulopathic state due to surgery and cardiopulmonary bypass (CPB). The beneficial effect of blood transfusion needs to be carefully balanced to avoid potential adverse reactions and complications such as transfusion reactions, transmitted infections, metabolic disequilibration, acute lung injury and negative impact on immunological function (4). This has led to the development of multiple algorithms that aim to reduce blood loss, promote blood conservation and aid rapid hemostasis. The present review discusses wide-ranging current multimodal strategies deployed pre-, intra- and postoperatively after complex aortic surgery to minimize transfusion and blood product use.

\section{PHARMACOTHERAPY TO INCREASE BLOOD VOLUME AND REDUCE BLOOD LOSS}

To decrease the exposure to allogeneic blood transfusion (ABT), a reduction of the perioperative blood loss is important. This reduction may be achieved through the pre-, peri- and postoperative management of pharmacological adjuvants that decrease bleeding and pharmacological alternatives to stimulate erythropoiesis and increase oxygen possible. Transfusion triggers use hemoglobin levels and platelet counts to guide treatment. Advanced measurements (whole body oxygen-carrying capacity, oxygen consumption, oxygen extraction ratios and oxygen delivery) represent accurate methods to estimate the need for transfusion. Intraoperative deployment of minimally invasive techniques and meticulous hemostasis reduce blood loss. Modified strategies for $\mathrm{CPB}$ are discussed such as using activated clotting time-guided heparinization, retrograde autologous priming of the $\mathrm{CPB}$ circuit, autotransfusion and cell salvage. Postoperative use of autologous transfusion strategies, and pharmacological adjuncts, such as aprotinin, lysine analogues epsilon-aminocaproic acid and tranexamic acid, are discussed. Specific correction of coagulation using fresh frozen plasma, cryoprecipitate or factor VIIa may be required. The multimodality approach to blood loss aims to optimize outcomes in highrisk aortic surgical patients.

Key Words: Aortic aneurysm; Aortic dissection; Aortic surgery; Blood conservation; Blood transfusion; Cardiac surgery

transport. Routine use of antiplatelet drugs is limited where possible preoperatively $(5,6)$. It is normal to continue acetylsalicylic acid preoperatively because there is good evidence that demonstrates adverse outcomes in cardiovascular and neurological end points when it is suddenly discontinued (5). In the elective setting, unless there are compelling specific reasons, other antiplatelet agents (ADP receptor inhibitors [eg, clopidogrel, prasugrel, ticagrelor]; phosphodiesterase inhibitors [eg, cilostazol]; adenosine reuptake inhibitors [eg, dipyridamole; thromboxane inhibitors [eg, terutoban]) are discontinued. Patients taking warfarin/vitamin $\mathrm{K}$ antagonists are bridged with intravenous heparin until the operation. This specifically applies to patients on vitamin $\mathrm{K}$ antagonists for metallic cardiac valves because the risk for thrombosis is high and has catastrophic consequences. Patients on warfarin for other indications, such as deep vein thrombosis, pulmonary emboli and atrial fibrillation, are bridged with low-molecular-weight heparins, with the dose omitted the day before the operation to normalize coagulation before surgery. Patients with low hemoglobin counts preoperatively need appropriate loading and supplementation with iron. Patients who are unable to receive blood products (eg, Jehovah's Witnesses) or have metabolic reason for pre-operative anemia require treatment with recombinant erythropoietin (5).

\section{RESTRICTIVE TRANSFUSION THERAPY}

Almost all randomized controlled trials (RCTs) have shown that the use of restrictive transfusion therapy in euvolemic surgical patients does not increase the rates of postoperative morbidity or mortality, or the length of hospital stay, while it does reduce both the percentage of transfused patients and the volume of allogeneic blood administered (5). Patients without signs of perioperative ischemia tolerate hemoglobin levels as low as $80 \mathrm{~g} / \mathrm{L}$ without increased postoperative morbidity or mortality in

Department of Cardiothoracic Surgery, Guy's and St Thomas' Hospital, London, United Kingdom

Correspondence: Dr Rizwan Attia, Department of Cardiothoracic Surgery, 6th Floor East Wing, St Thomas' Hospital, Westminster Bridge Road,

London SE1 7EH, United Kingdom. Telephone 44-0-207-188-0214, fax 44-0-207-188-1006, e-mail rizwanattia@doctors.org.uk 
cardiac interventions $(7,8)$. It has been assumed that patients with acute brain and/or cardiac dysfunction have worse outcomes being exposed to severe anemia (9). Following cardiac surgery, the general consensus is to aim for hemoglobin levels $\geq 80 \mathrm{~g} / \mathrm{L}$ to optimize oxygen flux and balance the risk for graft thrombosis, myocardial infarction, stroke and thrombotic events associated with chronic renal disease.

\section{FIBRINOGEN}

Fibrinogen promotes platelet aggregation and gives rise to fibrin polymers, which form the basis of clot formation when activated by thrombin (8). The substitution of crystalloid solutions and/or major bleeding implicate a loss and dilution of coagulation factors, including fibrinogen (7), potentially leading to coagulopathy, which is an independent risk factor for poor clinical outcome (8-12).

Additionally, preoperative fibrinogen levels are predictive of perioperative bleeding $(8,13,14)$. During an active bleeding episode, fibrinogen is the coagulation factor that is rapidly depleted, reaching levels as low as $>1 \mathrm{~g} / \mathrm{L}$; to effect hemostasis, a fibrinogen level of $1.5 \mathrm{~g} / \mathrm{L}$ to $4.5 \mathrm{~g} / \mathrm{L}$ is needed. The replacement can be obtained through cryoprecipitate or fibrinogen concentrate (7).

In patients undergoing surgery to repair a ruptured abdominal aortic aneurysm, the early aggressive administration of fresh frozen plasma (FFP) significantly reduced mortality rate from $39 \%$ to $15 \%$, suggesting that early correction of clotting factors may improve the clinical outcome (15). Furthermore, the pre- and postoperative infusion of fibrinogen in high dosages increased clot stability and reduced bleeding and transfusion requirements (15). In a large retrospective study involving patients undergoing cardiac surgery, the application of fibrinogen and prothrombin complex concentrates (PCCs) reduced the risk of thromboembolic incidents as well as the rates of transfusion (14).

RCT data have demonstrated that hemostasis is more effectively established with fibrinogen and FFP rather than FFP alone (16). However, the use of fibrinogen has been associated with increased risks for coronary ischemia (10), as well as with arterial and venous thromboembolisms when high doses were administered (17). These risks must be balanced at an individual level against the risk of lifethreatening bleeding diatheses. Most algorithms advocate aiming for fibrinogen levels of $\geq 4.5 \mathrm{~g} / \mathrm{L}$ after major cardiothoracic surgery to optimize the function of the coagulation cascade.

\section{SYNTHETIC LYSINE ANALOGUES}

Tranexamic acid (TXA) and epsilon-aminocaproic acid (EACA) are synthetic lysine analogues that competitively inhibit the binding of plasminogen to lysine residues on the fibrin surface, thereby preventing its conversion into active plasmin. TXA is 10 times more potent than EACA.

In cardiac surgery involving CPB, EACA administration has been shown to reduce $\mathrm{ABT}$ requirements and the rate of re-intervention for bleeding (18). Trials have shown EACA and TXA to have similar efficacy in reducing bleeding and ABT requirements (19). Interestingly, the blood-saving effects of both agents were even observed in patients treated with acetylsalicylic acid (20). TXA reduced the transfusion rate and the risk of re-intervention for bleeding in patients undergoing cardiac surgery with CPB compared with placebo (18). In myocardial revascularization surgery without $\mathrm{CPB}$, TXA administration reduced the risk of receiving ABT (21). Topical administration of TXA reduced postoperative bleeding, whereas it did not reduce ABT requirements (22). Patients receive the maximum therapeutic dose of TXA postoperatively and, in cases with massive ongoing hemorrhage, postoperatively a continuous TXA infusion can be considered until the coagulation screen is normalized with specific factor correction as guided by the coagulation profile and tests for clot stability.

\section{DESMOPRESSIN}

Desmopressin (1-desamino-8-D-arginine vasopressin [DDAVP]) is a synthetic analogue of the antidiuretic hormone vasopressin. It increases the plasma levels of factor VIII and von Willebrand factor. It does not affect blood pressure or cause vasoconstriction (23). The use of desmopressin in open heart surgery reduces postoperative blood loss. This is especially true in patients who have been on acetylsalicylic acid and those with excessive CPB times (namely the subgroups with higher platelet dysfunction) (24). These findings have been recapitulated in two meta-analyses $(15,25)$ and RCTs, and provide the basis for recommending DDAVP for reducing transfusion requirements (26-28).

\section{PCCS}

PCCs are plasma derivatives containing clotting factors II, IX and X, or clotting factors II, VII, IX and X, as well as protein C, protein S, antithrombin III and/or heparin to prevent thrombin formation (29). A normalization of international normalized ratio values is usually obtained within $10 \mathrm{~min}$ to $30 \mathrm{~min}$ of application (30-32). Most studies confirm the efficacy of PCCs to prevent bleeding in surgical or invasive procedures (33), and may be preferable to the use of recombinant factor VIIa and/or FFP in surgical patients (34). All patients have their prothrombin value measured postoperatively and corrected with FFP.

\section{AUTOLOGOUS TRANSFUSION}

Autologous transfusion (AT) refers to two distinct steps. First, whole blood is removed from the patient preoperatively and stored, with retransfusion postoperatively. During acute normovolemic hemodilution $(\mathrm{ANH})$, a volume of blood is extracted and anticoagulated, and simultaneously exchanged for a cell-free crystalloid or colloid solution during intervention to sustain normovolemia and can be used in patients undergoing major surgical procedures with an expected moderate to severe blood loss. ANH is usually performed after the induction of anesthesia, before the intraoperative phase of bleeding. The favoured technique is to create a moderate ANH of $25 \%$ to $30 \%$ final hematocrit (9). The operation is performed in a relatively hemodiluted state and whole blood, complete with platelet and clotting products, is reinfused postoperatively after discontinuation of CPB and heparin reversal with protamine sulphate. Large observational studies have demonstrated that the preoperative donation of two autologous blood units is effective in lowering ABT $(35,36)$.

The results of two meta-analyses of $42 \mathrm{RCTs}(37,38)$ showed that the use of ANH resulted in a small, significant reduction in transfusion rate. In combination with additional transfusion strategies, such as preoperative AT or the administration of TXA, the positive effect of ANH was nullified.

The second strategy involves the collection of blood that is shed during surgery followed by its immediate reinfusion after washing. Typically, the red blood cell component is retransfused (39). In concentrated blood autotransfusion, so-called 'cell salvage' the patient's blood is shed, mixed by a cell saver (CS) with anticoagulant, washed, filtered and concentrated, and followed by its immediate reinfusion. Potentially toxic products of injured cells and procoagulants are reduced, but essential blood elements, such as platelets, plasma proteins and clotting factors are also eliminated (40). However, there are devices that have increasingly become commercially available that aim to reconstitute and reinfuse the whole blood containing coagulation factors and platelets (41).

Results from a recent meta-analysis (37) showed that the use of preoperative AT reduced transfusion rates without increasing postoperative morbidity or mortality. Preoperative AT is contraindicated in cases with seropositivity, ongoing active bacterical infection, serious hemodynamic instability, a hemoglobin level $<100 \mathrm{~g} / \mathrm{L}$ and in a pediatric setting (9). Nonrandomized controlled studies involving aortic aneurysm repairs have been published, mostly reporting a reduction of transfusion volume with CS use and a decrease in the exposure to ABT (42-48). A meta-analysis of multiple RCTs has been published regarding the effect of CS use in elective infra-abdominal aortic aneurysm repairs found a near uniform reduction of ABT (49). Furthermore, the data show that the CS group of patients had a reduced length of ICU and hospital stay, and lower requirements for blood products (41). 


\section{MODIFICATION IN CPB CIRCUIT AND PRIME COMPOSITION}

Retrograde autologous priming (RAP) and venous antegrade priming are used to diminish hemodilution when instituting $\mathrm{CPB}$. Before the initiation of $\mathrm{CPB}$, these techniques are used to displace crystalloid prime within the $\mathrm{CPB}$ circuit with native blood (50). These perfusion techniques have increasingly gained interest since it was shown that a low hematocrit level during CPB has a detrimental effect on cognitive outcome and end-organ function (51-54).

Prospective randomized trials have demonstrated the efficacy of RAP (55). Patients consistently demonstrate higher hematocrit levels on CPB after RAP and VAP $(50,55)$, decreased intraoperative blood loss and shorter total hospital stay (56). RAP improves outcomes even in cases with known risk factors such as female sex, low body surface area and preoperative hematocrit, and irrespective of the complexity of CPB-conducted cardiac procedures (56). The appeal of RAP is its low cost and that all CPB circuits can be modified to accommodate RAP. The procedure can be performed with similar volume reduction without the use of vasopressors.

\section{MINIATURIZED CPB}

Miniaturized CPB (mCPB) is a concept of CPB based on a closed low prime volume circuit consisting of a rotary blood pump, coated systems (57) and a membrane oxygenator to reduce hemodilution $(53,58)$, mechanical blood trauma and blood-air contact (59). Because the venous blood returns through active drainage, there is no venous reservoir and cardiotomy suction is avoided (60).

A meta-analysis performed to analyze the impact on the rate of transfusion and on patients' cardiac and neurological outcome after cardiac surgery including $16 \mathrm{RCT}$ s comparing $\mathrm{mCPB}$ and standard cardiac surgery reported an association of $\mathrm{mCPB}$ and significant reductions in neurological damage, peak cardiac troponin levels and in the number of transfused patients in the setting of no differences in mortality between the cohorts (59). Other benefits that have been reported include higher mean arterial blood pressure during $\mathrm{CPB}$, lower consumption of vasoactive drugs and a reduced inflammatory response. A meta-analysis of 33 RCTs demonstrated lower risk for blood loss, postoperative stroke and mortality compared with conventional CPB (61).

The major difference from conventional $\mathrm{CPB}$ is a lack of a venous reservoir and cardiotomy suction; this leads to significantly decreased tubing length and decreased priming volume. The minimal extracorporeal circulation provides a closed circuit with no blood-air contact. Cell salvage of suctioned blood avoids contact of activated blood that may also be contaminated with tissue debris and lipids. The reduction in bleeding and transfusion are likely to be due to reduced hemodilution and coagulation cascade activation. The use of $\mathrm{mCPB}$ requires considerable change to surgical practice. Suturing may be difficult due to blood in the operative field. The heart cannot be completely emptied without the use of a cardiac vent. There is increased risk for gas embolism from venous air intake. Due to these limitations, it has only been studied in coronary artery bypass surgery and aortic valve replacements. Its role remains undefined in long, complex operative procedures with extensive dissection of tissue planes or emergent cases.

\section{ALTERATION OF COOLING/NEUROPROTECTIVE STRATEGIES TO OPTIMIZE EFFECTS ON THE COAGULATION CASCADE}

Antegrade selective cerebral perfusion, in combination with profoundto-deep hypothermic circulatory arrest (DHCA), has been the gold standard and the method of choice for surgery of aortic pathologies involving the transverse arch during the past decade $(62,63)$. Detailed discussion of neuroprotective strategies is beyond the scope of the present review (we refer readers to a published review in this area [64]). Considering the use of antegrade selective cerebral perfusion and DHCA several studies presented excellent results in total aortic arch replacement/complex aortic surgery (65). Recently, there has been a shift among aortic specialists toward more moderate body circulatory arrest, advocating the use of moderate to mild hypothermia $\left(28^{\circ} \mathrm{C}\right.$ to $\left.35^{\circ} \mathrm{C}\right)$ during interventions on the aortic arch $(66-68)$. This concept has similarly been introduced for the emergency repair of acute aortic dissections (69). Mortality in these studies was low, as were stroke and paraplegia rates. However, as operative times increase, so does the risk for adverse neurological outcomes. Nonetheless, it should be noted that these changes in temperature management similarly increased the risk for ischemic spinal cord injuries and ischemic visceral damage during prolonged circulatory arrest (65).

Recent analysis of the hemi-arch replacement with unilateral selective cerebral perfusion (SCP) at a moderate temperature of $28.6^{\circ} \mathrm{C}$ and a deep average temperature of $24.3^{\circ} \mathrm{C}$ found similar operative mortalities for elective and urgent cases, no difference in the incidence of temporary neurological deficits and a similar re-exploration rate for bleeding (70). However, patients with moderate versus deep temperature management experienced a significantly lower rate of permanent neurological deficits (70).

Other clinical studies suggest an advantage for bilateral perfusion with regard to quality of life in cases that require prolonged SCP of $>40 \mathrm{~min}$ (71) and $>40 \mathrm{~min}$ to $50 \mathrm{~min}$ (72). Obviously, bilateral antegrade SCP is currently the method of choice for cerebral protection, especially in complex cases of total arch replacement from $>30 \mathrm{~min}$ to 40 min, whereas unilateral SCP may be sufficient if circulatory arrest is limited (73). The use of unilateral SCP increases the risk for nonadequate cerebral perfusion and, therefore, requires adequate cerebral blood flow monitoring to change to bilateral SCP if required (65). Detailed discussion of cerebral protection strategies and cerebral monitoring are outside the scope of the present review, but readers are referred to other comprehensive literature regarding this topic (74).

\section{MINIMALLY INVASIVE PROCEDURES TO REDUCE PERIOPERATIVE BLEEDING}

Ministernotomy procedures through an inverted C-, L- or J-shaped hemisternotomy aim to reduce operative trauma and expedite recovery. These techniques are typically used for isolated aortic valve replacements; however, enthusiastic centres have performed ascending aortic replacements via this approach (75). The data show a significant reduction in the length of ICU stay and a trend toward reduction in postoperative blood loss within the first $24 \mathrm{~h}$ in ministernotomy patients compared with conventional sternotomy patients (76).

\section{USE OF TOPICAL ADJUNCTS FOR HEMOSTASIS}

There is a wide range of local hemostatic adjuncts (LHAs) to achieve hemorrhage control in surgery. LHAs include collagen, gelatin- or cellulose-based products, fibrin and synthetic glues or adhesives that can be used for both external and internal bleeding, while polysaccharide-based and inorganic hemostatics are primarily used and approved for external bleeding. In cardiac surgery, LHAs are mainly used to reduce bleeding from the sternum in the form of bone wax (2). LHAs are increasingly used in surgical procedures (77-83). Collagen-based agents trigger platelet aggregation, resulting in clot formation when they come in contact with a bleeding surface. They are often used in combination with a procoagulant substance, such as thrombin, to enhance the hemostatic effect. A positive hemostatic effect has been shown in several studies $(78,84,85)$. Gelatin-based products can be used alone or in combination with a procoagulant substance. The expansion of the gelatin in contact with blood reduces blood flow and, in combination with a thrombin-based component, enhances hemostasis. A similar or superior hemostatic effect has been observed compared with collagen-based agents (80-82). Fibrin and synthetic glues or adhesives have both hemostatic and sealant properties, and their significant effect on hemostasis has been shown in several human RCTs involving vascular, bone, skin and visceral surgery $(83,86,87)$. 


\section{MULTIDISCIPLINARY SUPPORT}

The importance of a multidisciplinary team that provides organized blood transfusion management and hemostatic support is vital. In general, access to blood conservation measures, the implementation of transfusion coordinators and the organization of a multidisciplinary network can facilitate education about available transfusion options, recognize different approaches and promote blood conservation and alternatives to transfusion.

One possible strategy would be the installation of specially trained transfusion coordinators providing advanced knowledge and skills to guarantee optimal care to patients, families and medical staff. It is important to anticipate possible transfusion needs and have a blood conservation strategy in place. A current and accurate database for patients enrolled in the blood conservation program is important to ensure further studies are performed based on good contemporary prospective data, and blood/blood product use audited according to set criteria and standards.

Studies have shown that the placement of transfusion coordinators and implementation of blood conservation strategies has led to a decrease in the use of ABT of up to $24 \%$ after 12 months in patients undergoing knee surgery, $23 \%$ in coronary artery bypass grafting and 14 in abdominal aortic aneurysm (35). This was achieved in a setting of reducing postoperative infection rates and length of hospital stay (35).

\section{DISCUSSION AND CONCLUSION}

Over the past decade, mounting evidence points to the significant disadvantages associated with blood transfusions. In cardiothoracic surgery, especially complex aortic work, the data are convincing that there are immediate and long-term negative consequences of transfusion. Recent developments have significantly improved our techniques of blood conservation in cardiac operations and could help to substantially decrease the number of ABTs and improve patient outcomes.

DISCLOSURES: The authors declare no potential conflicts of interest with respect to the research, authorship and publication of this article.

\section{REFERENCES}

1. Clagett GP, Valentine RJ, Jackson MR, Mathison C, Kakish HB, Bengtson TD. A randomized trial of intraoperative autotransfusion during aortic surgery. J Vasc Surg 1999;29:22-30.

2. Papalexopoulou N, Attia RQ, Bapat VN. Successful surgical repair of acute type A aortic dissection without the use of blood products. Ann R Coll Surg Engl 2013;95:127-9.

3. Horvath KA, Acker MA, Chang H, et al. Blood transfusion and infection after cardiac surgery. Ann Thorac Surg 2013;95:2194-201.

4. Blajchman MA, Vamvakas EC. The continuing risk of transfusiontransmitted infections. N Engl J Med 2006;355:1303-5.

5. Ferrandis R, Llau JV, Mugarra A. Perioperative management of antiplatelet-drugs in cardiac surgery. Curr Cardiol Rev 2009;5:125-32.

6. Eagle KA, Guyton RA, Davidoff R, et al. ACC/AHA 2004 guideline update for coronary artery bypass graft surgery: A report of the American College of Cardiology/American Heart Association Task Force on Practice Guidelines (Committee to Update the 1999 Guidelines for Coronary Artery Bypass Graft Surgery). Circulation 2004:e340-437.

7. Retter A, Wyncoll D, Pearse R, et al. Guidelines on the management of anaemia and red cell transfusion in adult critically ill patients. Br J Haematol 2013;160:445-64.

8. Hajjar LA, Vincent J-L, Galas FRBG, et al. Transfusion requirements after cardiac surgery: The TRACS randomized controlled trial. JAMA 2010;304:1559-67.

9. Leal-Noval SR, Muñoz M, Asuero M, et al. Spanish consensus statement on alternatives to allogeneic blood transfusion: The 2013 update of the "Seville Document". Blood Transfus 2013;11:585-610.

10. Levy JH, Szlam F, Tanaka KA, Sniecienski RM. Fibrinogen and hemostasis: A primary hemostatic target for the management of acquired bleeding. Anesth Analg 2012;114:261-74.

11. Johansson PI. Coagulation monitoring of the bleeding traumatized patient. Curr Opin Anaesthesiol 2012;25:235-41.

12. Kozek-Langenecker SA, Jungheinrich C, Sauermann W, Van der Linden P. The effects of hydroxyethyl starch 130/0.4 (6\%) on blood loss and use of blood products in major surgery: A pooled analysis of randomized clinical trials. Anesth Analg 2008;107:382-90.

13. Frith D, Brohi K. The pathophysiology of trauma-induced coagulopathy. Curr Opin Crit Care 2012;18:631-6.

14. Görlinger K, Dirkmann D, Hanke AA, et al. First-line therapy with coagulation factor concentrates combined with point-of-care coagulation testing is associated with decreased allogeneic blood transfusion in cardiovascular surgery: A retrospective, single-center cohort study. Anesthesiology 2011;115:1179-91

15. Mell MW, O'Neil AS, Callcut RA, et al. Effect of early plasma transfusion on mortality in patients with ruptured abdominal aortic aneurysm. Surgery 2010;148:955-62.

16. Lancé MD, Ninivaggi M, Schols SEM, et al. Perioperative dilutional coagulopathy treated with fresh frozen plasma and fibrinogen concentrate: A prospective randomized intervention trial. Vox Sang 2012;103:25-34.

17. Weiss G, Lison S, Glaser M, et al. Observational study of fibrinogen concentrate in massive hemorrhage: evaluation of a multicenter register. Blood Coagul Fibrinolysis 2011;22:727-34.

18. Henry D, Carless P, Fergusson D, Laupacis A. The safety of aprotinin and lysine-derived antifibrinolytic drugs in cardiac surgery: A meta-analysis. CMAJ 2009;180:183-93.

19. Fergusson DA, Hébert PC, Mazer CD, Fremes S, et al. A comparison of aprotinin and lysine analogues in high-risk cardiac surgery. N Engl J Med 2008;358:2319-31.

20. Mcllroy DR, Myles PS, Phillips LE, Smith JA. Antifibrinolytics in cardiac surgical patients receiving aspirin: A systematic review and meta-analysis. Br J Anaesth 2009;102:168-78.

21. Adler Ma SC, Brindle W, Burton G, et al. Tranexamic acid is associated with less blood transfusion in off-pump coronary artery bypass graft surgery: A systematic review and meta-analysis. J Cardiothorac Vasc Anesth 2011;25:26-35.

22. Abrishami A, Chung F, Wong J. Topical application of antifibrinolytic drugs for on-pump cardiac surgery: A systematic review and meta-analysis. Can J Anaesth 2009;56:202-12.

23. Cattaneo M. The use of desmopressin in open-heart surgery. Haemophilia 2008;(14 Suppl 1):40-7.

24. Wademan BH, Galvin SD. Desmopressin for reducing postoperative blood loss and transfusion requirements following cardiac surgery in adults. Interact Cardiovasc Thorac Surg 2014;18:360-70.

25. Ozier Y, Hunt BJ. Against: Fibrinogen concentrate for management of bleeding: against indiscriminate use. J Thromb Haemost 2011;9:6-8.

26. Carless PA, Henry DA, Moxey AJ et al. Desmopressin for minimising perioperative allogeneic blood transfusion. Cochrane Database Syst Rev 2004;(1):CD001884.

27. Levi M, Cromheecke ME, de Jonge E et al. Pharmacological strategies to decrease excessive blood loss in cardiac surgery: A meta-analysis of clinically relevant endpoints. Lancet 1999;354:1940-7.

28. Cattaneo M, Harris AS, Strömberg U, Mannucci PM. The effect of desmopressin on reducing blood loss in cardiac surgery - a metaanalysis of double-blind, placebo-controlled trials. Thromb Haemost 1995;74:1064-70.

29. Kamiya H, Kofidis T, Haverich A, Klima U. Preliminary experience with the mini-extracorporeal circulation system (Medtronic resting heart system). Interact Cardiovasc Thorac Surg 2006;5:680-2.

30. Bhagirath VC, O'Malley L, Crowther MA. Management of bleeding complications in the anticoagulated patient. Semin Hematol 2011;48:285-94.

31. Pabinger I, Brenner B, Kalina U, et al. Prothrombin complex concentrate (Beriplex $\mathrm{P} / \mathrm{N})$ for emergency anticoagulation reversal: A prospective multinational clinical trial. J Thromb Haemost 2008;6:622-31.

32. Lankiewicz MW, Hays J, Friedman KD, Tinkoff G, Blatt PM. Urgent reversal of warfarin with prothrombin complex concentrate. J Thromb Haemost 2006;4:967-70. 
33. Lubetsky A, Hoffman R, Zimlichman R, et al. Efficacy and safety of a prothrombin complex concentrate (Octaplex) for rapid reversal of oral anticoagulation. Thromb Res 2004;113:371-8.

34. Society of Thoracic Surgeons Blood Conservation Guideline Task Force, Ferraris VA, Brown JR, Despotis GJ, et al. 2011 update to the Society of Thoracic Surgeons and the Society of Cardiovascular Anesthesiologists blood conservation clinical practice guidelines. Ann Thorac Surg 2011;91:944-82.

35. Freedman J, Luke K, Escobar M, Vernich L, Chiavetta JA. Experience of a network of transfusion coordinators for blood conservation (Ontario Transfusion Coordinators [ONTraC]). Transfusion 2008;48:237-50.

36. Dietrich W, Thuermel K, Heyde S, Busley R, Berger K. Autologous blood donation in cardiac surgery: Reduction of allogeneic blood transfusion and cost-effectiveness. J Cardiothorac Vasc Anesth 2005;19:589-96.

37. Carless P, Moxey A, O'Connell D, Henry D. Autologous transfusion techniques: A systematic review of their efficacy. Transfus Med 2004;14:123-44.

38. Segal JB, Blasco-Colmenares E, Norris EJ, Guallar E. Preoperative acute normovolemic hemodilution: A meta-analysis. Transfusion 2004;44:632-44.

39. Martin K, Keller E, Gertler R, Tassani P, Wiesner G. Efficiency and safety of preoperative autologous blood donation in cardiac surgery: A matched-pair analysis in 432 patients. Eur J Cardiothorac Surg 2010;37:1396-401.

40. Brzica SM, Pineda AA, Taswell HF. Autologous blood transfusion. Mayo Clin Proc 1976;51:723-37.

41. Shantikumar S, Patel S, Handa A. The role of cell salvage autotransfusion in abdominal aortic aneurysm surgery. Eur J Vasc Endovasc Surg 2011;42:577-84.

42. Thomas GI, Jones TW, Stavney LS, Manhas DR, Carson SA. Experiences with autotransfusion during abdominal aortic aneurysm resection. Am J Surg 1980;139:628-33

43. Shuhaiber JH, Whitehead SM. The impact of introducing an autologous intraoperative transfusion device to a community hospital. Ann Vasc Surg 2003;17:424-9.

44. Tawfick WA, O'Connor M, Hynes N, Sultan S. Implementation of the Continuous AutoTransfusion System (C.A.T.S) in open abdominal aortic aneurysm repair: An observational comparative cohort study. Vasc Endovascular Surg 2008;42:32-9.

45. Allums JA, Gordon FT, Moore CH, Marino C. Intraoperative autotransfusion for abdominal aortic aneurysm repair. Tex Med 1978;74:55-8.

46. Marković M, Davidović L, Savić N, Sindjelić R, Ille T, Dragas M. Intraoperative cell salvage versus allogeneic transfusion during abdominal aortic surgery: Clinical and financial outcomes. Vascular 2009;17:83-92.

47. McMahon AJ, McCormick JS. Combined predeposit and salvage autotransfusion in elective aortic aneurysm repair. JR Coll Surg Edinb 1993;38:71-4.

48. Serrano FJ, Moñux G, Aroca M. Should the cell saver autotransfusion system be routinely used in elective aortic surgery? Ann Vasc Surg 2000;14:663-8.

49. Takagi H, Sekino S, Kato T, Matsuno Y, Umemoto T. Intraoperative autotransfusion in abdominal aortic aneurysm surgery: Meta-analysis of randomized controlled trials. Arch Surg 2007;142:1098-101.

50. Teman N, Delavari N, Romano M, Prager R, Yang B, Haft J. Effects of autologous priming on blood conservation after cardiac surgery. Perfusion 2014;29:333-9.

51. Habib RH, Zacharias A, Schwann TA, Riordan CJ, Durham SJ, Shah A. Adverse effects of low hematocrit during cardiopulmonary bypass in the adult: Should current practice be changed? J Thorac Cardiovasc Surg 2003;125:1438-50.

52. Loor G, Li L, Sabik JF, Rajeswaran J, Blackstone EH, Koch CG. Nadir hematocrit during cardiopulmonary bypass: End-organ dysfunction and mortality. J Thorac Cardiovasc Surg 2012;144:654-4.

53. Karkouti K, Beattie WS, Wijeysundera DN, et al. Hemodilution during cardiopulmonary bypass is an independent risk factor for acute renal failure in adult cardiac surgery. J Thorac Cardiovasc Surg 2005;129:391-400.

54. Swaminathan M, Phillips-Bute BG, Conlon PJ, Smith PK, Newman MF, Stafford-Smith M. The association of lowest hematocrit during cardiopulmonary bypass with acute renal injury after coronary artery bypass surgery. Ann Thorac Surg 2003;76:784-91.
55. Sun P, Ji B, Sun Y, Zhu X, Liu J, Long C, et al. Effects of retrograde autologous priming on blood transfusion and clinical outcomes in adults: A meta-analysis. Perfusion 2013;28:238-43.

56. Vandewiele K, Bové T, De Somer FMJJ, et al. The effect of retrograde autologous priming volume on haemodilution and transfusion requirements during cardiac surgery. Interact Cardiovasc Thorac Surg 2013;16:778-83.

57. Pappalardo F, Valle Della P, Crescenzi G, et al. Phosphorylcholine coating may limit thrombin formation during high-risk cardiac surgery: A randomized controlled trial. Ann Thorac Surg 2006;81:886-91.

58. Koch CG, Li L, Duncan AI, Mihaljevic T, et al. Morbidity and mortality risk associated with red blood cell and blood-component transfusion in isolated coronary artery bypass grafting. Crit Care Med 2006;34:1608-16.

59. Albes JM, Stöhr IM, Kaluza M, et al. Physiological coagulation can be maintained in extracorporeal circulation by means of shed blood separation and coating. J Thorac Cardiovasc Surg 2003;126:1504-12.

60. De Somer F, Van Belleghem Y, Caes F, et al. Tissue factor as the main activator of the coagulation system during cardiopulmonary bypass. J Thorac Cardiovasc Surg 2002;123:951-8.

61. Biancari F, Rimpiläinen R. Meta-analysis of randomised trials comparing the effectiveness of miniaturised versus conventional cardiopulmonary bypass in adult cardiac surgery. Heart 2009;95:964-9.

62. Bachet J, Guilmet D, Goudot B, et al. Antegrade cerebral perfusion with cold blood: A 13-year experience. Ann Thorac Surg 1999;67:1874-8

63. Kazui T, Washiyama N, Muhammad BA, Terada H, Yamashita K, Takinami M. Improved results of atherosclerotic arch aneurysm operations with a refined technique. J Thorac Cardiovasc Surg 2001;121:491-9.

64. Conlon N, Grocott HP, Mackensen GB. Neuroprotection during cardiac surgery. Exp Rev CardiovascTher 2008;6:503-20.

65. Luehr M, Bachet J, Mohr F-W, Etz CD. Modern temperature management in aortic arch surgery: The dilemma of moderate hypothermia. Eur J Cardiothorac Surg 2014;45:27-39.

66. Zierer A, Detho F, Dzemali O, Aybek T, Moritz A, Bakhtiary F Antegrade cerebral perfusion with mild hypothermia for aortic arch replacement: Single-center experience in 245 consecutive patients. Ann Thorac Surg 2011;91:1868-73.

67. Urbanski PP, Lenos A, Bougioukakis P, Neophytou I, Zacher M, Diegeler A. Mild-to-moderate hypothermia in aortic arch surgery using circulatory arrest: A change of paradigm? Eur J Cardiothorac Surg 2012;41:185-91.

68. Leshnower BG, Myung RJ, Kilgo PD, et al. Moderate hypothermia and unilateral selective antegrade cerebral perfusion: A contemporary cerebral protection strategy for aortic arch surgery. Ann Thorac Surg 2010;90:547-54.

69. Panos A, Murith N, Bednarkiewicz M, Khatchatourov G. Axillary cerebral perfusion for arch surgery in acute type A dissection under moderate hypothermia. Eur J Cardiothorac Surg 2006;29:1036-9.

70. Leshnower BG, Myung RJ, Thourani VH, et al. Hemiarch replacement at $28^{\circ} \mathrm{C}$ : An analysis of mild and moderate hypothermia in 500 patients. Ann Thorac Surg 2012;93:1910-5.

71. Krähenbühl ES, Clément M, Reineke D, et al. Antegrade cerebral protection in thoracic aortic surgery: Lessons from the past decade. Eur J Cardiothorac Surg 2010;38:46-51.

72. Malvindi PG, Scrascia G, Vitale N. Is unilateral antegrade cerebral perfusion equivalent to bilateral cerebral perfusion for patients undergoing aortic arch surgery? Interact Cardiovasc Thorac Surg 2008;7:891-7.

73. Misfeld M, Leontyev S, Borger MA, et al. What is the best strategy for brain protection in patients undergoing aortic arch surgery? A single center experience of 636 patients. Ann Thorac Surg 2012;93:1502-8.

74. Apostolakis E, Akinosoglou K. The methodologies of hypothermic circulatory arrest and of antegrade and retrograde cerebral perfusion for aortic arch surgery. Ann Thorac Cardiovasc Surg 2008;14:138-48.

75. Perrotta S, Lentini S, Rinaldi M, et al. Treatment of ascending aorta disease with Bentall-De Bono operation using a mini-invasive approach. J Cardiovasc Med (Hagerstown). 2008;9:1016-22.

76. Khoshbin E, Prayaga S, Kinsella J, Sutherland FWH.

Mini-sternotomy for aortic valve replacement reduces the length of stay in the cardiac intensive care unit: Meta-analysis of randomised controlled trials. BMJ Open 2011;1:e000266. 
77. Recinos G, Inaba K, Dubose J, Demetriades D, Rhee P. Local and systemic hemostatics in trauma: A review. Ulus Travma Acil Cerrahi Derg 2008;14:175-81.

78. Smith KJ, Skelton HG, Barrett TL, Welch M, Beard J. Histologic and immunohistochemical features in biopsy sites in which bovine collagen matrix was used for hemostasis. J Am Acad Dermatol 1996;34:434-8.

79. Sherman R, Chapman WC, Hannon G, Block JE. Control of bone bleeding at the sternum and iliac crest donor sites using a collagenbased composite combined with autologous plasma: Results of a randomized controlled trial. Orthopedics 2001;24:137-41.

80. Oz MC, Cosgrove DM, Badduke BR, et al. Controlled clinical trial of a novel hemostatic agent in cardiac surgery. The Fusion Matrix Study Group. Ann Thorac Surg 2000;69:1376-82.

81. Pursifull NF, Morris MS, Harris RA, Morey AF. Damage control management of experimental grade 5 renal injuries: Further evaluation of FloSeal gelatin matrix. J Trauma 2006;60:346-50.

82. Weaver FA, Hood DB, Zatina M, Messina L, Badduke B.

Gelatin-thrombin-based hemostatic sealant for intraoperative bleeding in vascular surgery. Ann Vasc Surg 2002;16:286-93.
83. Schenk WG, Burks SG, Gagne PJ, Kagan SA, Lawson JH, Spotnitz WD. Fibrin sealant improves hemostasis in peripheral vascular surgery: A randomized prospective trial. Ann Surg 2003;237:871.

84. Chapman WC, Clavien PA, Fung J, Khanna A, Bonham A. Effective control of hepatic bleeding with a novel collagen-based composite combined with autologous plasma: Results of a randomized controlled trial. Arch Surg 2000;135:1200-4.

85. CoStasis Multi-center Collaborative Writing Committee. A novel collagen-based composite offers effective hemostasis for multiple surgical indications: Results of a randomized controlled trial. Surgery 2001;129:445-50.

86. Drake DB, Wong LG. Hemostatic effect of Vivostat patient-derived fibrin sealant on split-thickness skin graft donor sites. Ann Plast Surg 2003;50:367-72.

87. Molloy DO, Archbold HAP, Ogonda L, McConway J, Wilson RK, Beverland DE. Comparison of topical fibrin spray and tranexamic acid on blood loss after total knee replacement: A prospective, randomised controlled trial. J Bone Joint Surg Br 2007;89:306-9. 